\title{
Fluorescent Fatty Acid Transfer from Bovine Serum Albumin to Phospholipid Vesicles: Collision or Diffusion Mediated Uptake
}

\author{
Bassam M.Elmadhoun ${ }^{1}$, Manal A. Swairjo², and Frank J. Burczynski ${ }^{3}$ \\ ${ }^{1}$ Faculty of Pharmacy, Batterjee Medical College for Science \& Technology, Jeddah, Kingdom of Saudi Arabia. \\ ${ }^{2}$ Graduate College of Biomedical Sciences, Western University of Health Sciences, 309 E. 2nd Street, Pomona, CA, USA. \\ ${ }^{3}$ Faculty of Pharmacy, and Department of Pharmacology and Therapeutics, Faculty of Medicine, University of Manitoba, \\ Winnipeg, Manitoba, Canada.
}

Received, May 1, 2012; Revised, June 22, 2012, Accepted, July 6, 2012; Published, July 9, 2012.

\begin{abstract}
Purpose: The extent of palmitate uptake by hepatocytes is dependent upon the surface charge of the extracellular binding protein. Specifically, hepatocyte uptake is greater when palmitate is bound to cationic binding proteins than when it is bound to anionic proteins. To further understand the role of protein surface charge on the uptake process of protein-bound ligands, we examined the rate of transfer of fluorescent anthroyloxy palmitic acid (AOPA) in the presence of anionic and cationic extracellular proteins to model membranes containing different surface charged groups. Method: AOPA transfer rate in the presence of bovine serum albumin $(A L B$; isoelectric point $\mathrm{pI}=4.8-5.0)$ or modified $\mathrm{ALB}\left(\mathrm{ALB}_{\mathrm{e}} ; \mathrm{pI}=7.0-7.5\right)$ to negative, positive and neutral lipid vesicles was investigated using a fluorescence resonance energy transfer assay. Results: The rate of AOPA transfer from both proteins was decreased when ionic strength was increased; directly dependent on the concentration of acceptor lipid vesicles; and was affected by both the lipid membrane surface charge and protein-bound concentration. Conclusion: The data support the notion that AOPA transfer from binding proteins to lipid membranes occurred through two concomitant processes, aqueous diffusion of the unbound ligand (diffusion-mediated process) and a collisional interaction between the protein-ligand complex and acceptor membrane. The contribution of diffusional mediated transfer to the overall uptake process was determined to be 3 to 4 times less than the contribution of a collisional interaction. This study strengthened the hypothesis that charged amino acid residues on proteins are important for effective collisional interaction between proteinligand complexes and cell membranes through which more free ligand could be supplied for the uptake process.
\end{abstract}

This article is open to POST-PUBLICATION REVIEW. Registered readers (see "For Readers") may comment by clicking on ABSTRACT on the issue's contents page.

\section{INTRODUCTION}

Nonesterified long-chain fatty acids (LCFA) are a major energy source for most mammalian cells. In plasma these substrates are highly protein bound owing to their high lipophilicity. Extracellular protein binding makes understanding their uptake process very complicated. As such uptake of highly lipophilic ligands has been a controversial area of investigation.

Prior to entering the cell, these substrates must traverse several sequential barriers. One of the steps involved in the uptake process is dissociation from the extracellular protein-binding site. Whether the dissociation step is mediated by interactions with the surface charged groups on the outer membrane leaflet of the cell is not clear (1). Although it is generally accepted that uptake does not involve the protein-ligand complex, several reports provide strong evidence that ligand uptake may occur directly from the protein-ligand fraction (2-6).

Evidence supporting the hypothesis that an ionic interaction between the protein-ligand complex and the cell surface is likely mediating the supply of ligand from the protein-bound fraction to the cell has been reported (2). Hepatocyte uptake of $\left[{ }^{3} \mathrm{H}\right]$-palmitate was shown to be greater when the binding protein contained a net positive charge at physiological $\mathrm{pH}$ compared with a net negative charge. The present studies were undertaken to further explore the uptake process.

Corresponding Author: F.J. Burczynski, Ph.D., Faculty of Pharmacy, University of Manitoba, 750 McDermot Avenue, Winnipeg, Manitoba, E-Mail: burczyn@cc.umanitoba.ca 
The objective was to determine if an ionic interaction between extracellular binding proteins and acceptor membranes was associated with an increase in uptake rate. The transfer rate of LCFAs from albumin to model membranes was investigated using a fluorescence resonance energy transfer assay. We explored the transfer rate of anthroyloxy labeled palmitic acid (AOPA) bound to ALB (isoelectric point, $\mathrm{pI}=4.8$ ) or modified ALB $(\mathrm{pI}=7.5)$ to negative, positive, and neutral lipid vesicles. This technique has been successfully used to study the rate and mechanism of transfer of many important physiological substrates such as cholesterol (7); phospholipids (8); sphingomyeline (9); short-chain fatty acids (10); and long-chain fatty acids $(11,12)$ between various binding proteins and phospholipid vesicles.

\section{MATERIALS AND METHODS}

Fluorescently labeled 16-(9-anthroyloxy) palmitic acid (AOPA) was purchased from Molecular Probes, Inc. (Eugene, OR). Synthetic 1,2-dioleoylsn-glycero-3-phosphatidycholine (DOPC), synthetic 1,2-dioleoyl-sn-glycero-3-phosphatidyserine

(DOPS), synthetic 1,2-dioleoyl-sn-glycero-3phosphatidyethanolamine (DOPE), and 1,2dioleoyl-sn-glycero-3-phosphatidyethanolamine-N(7-nitro-2,1,3-benzoxadiazole-4-yl) (NBD-DOPE) were obtained from Avanti Polar Lipids (Birmingham, AL). Bovine serum albumin (ALB, essentially fatty acid-free) and stearylamine (SA) were purchased from Sigma (St. Louis, MO.). The aqueous buffer used throughout all experiments was phosphate buffered saline (PBS) having a composition of (in mM: $137 \mathrm{NaCl}, 2.68 \mathrm{KCl}, 1.65$ $\mathrm{KH}_{2} \mathrm{PO}_{4}, 8.92 \mathrm{Na}_{2} \mathrm{HPO}_{4}$ and $3 \mathrm{NaN}_{3}$ ) with $\mathrm{pH}$ adjusted to 7.4 using $0.1 \mathrm{M} \mathrm{NaOH}$.

\section{Chemical modification of albumin}

Albumin was modified by activating the carboxyl groups with carbodiimide treatment and then aminating them with ethylenediamine as previously described (13). Briefly, anhydrous ethylenediamine $(66.6 \mathrm{ml})$ was added to $500 \mathrm{ml}$ distilled water. The $\mathrm{pH}$ of the resulting solution was adjusted to 4.75 with approximately $350 \mathrm{ml} 6 \mathrm{~N} \mathrm{HCl}$. ALB $(2 \mathrm{~g})$ and 1-ethyl-3 (3-dimethyl-amino propyl)carbodiimide $(0.725 \mathrm{~g})$ was added to this solution. The mixture was allowed to react for approximately
10 minutes with gentle stirring. The reaction was terminated by the addition of $30 \mathrm{ml} 4 \mathrm{M}$ acetate buffer $(\mathrm{pH}=4.75)$. The modified albumin $\left(\mathrm{ALB}_{\mathrm{e}}\right)$ solution was dialyzed against distilled water at $4^{\circ} \mathrm{C}$, concentrated, lyophilized, and stored at $-20^{\circ} \mathrm{C}$ until use.

\section{Determination of molecular weight}

Mass measurements of ALB and $\mathrm{ALB}_{\mathrm{e}}$, dissolved in $5 \%$ acetic acid in methanol/water $(1: 1 \mathrm{v} / \mathrm{v})$, were conducted on an orthogonal injection electrospray ionization time-of-flight (ESI/TOF III) mass spectrometer (14). Prior to analysis, residual sodium, potassium, and phosphate were removed from proteins by ultrafiltration using $25 \mathrm{mM}$ ammonium bicarbonate buffer. Analysis was performed at a declustering voltage of $190 \mathrm{eV}$. Molecular masses were obtained by deconvolution using a computer program as previously described (14).

\section{Determination of extent of modification}

Amino acid modifications of $\mathrm{ALB}_{\mathrm{e}}$ were identified by peptide mapping as follows. Tryptic digestions of $\mathrm{ALB}_{\mathrm{e}}$ and ALB (as a control) were conducted in $25 \mathrm{mM}$ ammonium bicarbonate solution (1\% trypsin, w/w) at $37^{\circ} \mathrm{C}$ for 24 hours and the digest analyzed by mass spectrometry on a SCIEX prototype tandem quadrupole/TOF mass spectrometer (QqTOF) coupled to a matrix assisted laser desorption ionization (MALDI) ion source. A 2,5 dihydrobenzoic acid (DHB) solution (100 $\mathrm{mg} / \mathrm{ml}$ in acetone) was used as the matrix. Peptide fragments for sequence identification were formed by collision-induced dissociation (CID) with Argon as the collision gas and collision energies of 50-180 $\mathrm{eV}$.

\section{Determination of isoelectric point (pI)}

The isoelectric points (pI) of ALB and $\mathrm{ALB}_{\mathrm{e}}$ were determined on IEF gels using a model 111 Mini IEF-cell (BIO-RAD) and BioLyte 3/10 obtained from Bio-Rad Laboratories (California, USA). The gels were stained with Coomassie blue R-250.

\section{Preparation of large unilamellar vesicles (LUVs)}

Lipid vesicles were prepared by the mechanical dispersion method as described by Swairjo et al. (15). Briefly, 65 mol \% synthetic 1,2-dioleoyl-snglycero-3-phosphatidycholine (DOPC), $10 \mathrm{~mol} \%$ 1,2-dioleoyl-sn-glycero-3-phosphatidyethanolamine 
-N-(7-nitro-2,1,3-benzoxadiazole-4-yl) (NBDDOPE), and $25 \mathrm{~mol} \%$ 1,2-dioleoyl-sn-glycero-3phospho-L-serine sodium salt (DOPS, in the case of negatively charged lipid vesicles, -veLUVs), or stearylamine (SA, in the case of positively charged lipid vesicles, +veLUVs), or 1,2-dioleoyl-snglycero-3-phosphatidyethanolamine (DOPE, in the case of neutral lipid vesicles, neuLUVs) in chloroform were dried in a rotary evaporator under nitrogen gas to form a thin lipid film on the inner wall of a rounded-bottom flask. PBS containing $0.02 \%$ sodium azide $\left(\mathrm{NaN}_{3}\right), 0.1 \mathrm{mM}$ dithiothreitol (DTT), and $0.1 \mathrm{mM}$ ethylenediamine-tetraacetic acid (EDTA) was added to a final concentration of $3 \mathrm{mM}$ total lipids. The liposome dispersion was extruded 11 times through a polycarbonate membrane (Nuclepore, 200-nm pore size) using a mini-extruder (Avanti Polar Lipids, Alabaster, Al, USA) to obtain a homogenous population of large unilamellar vesicles. After extrusion, the vesicles were concentrated in an Amicon centrifugal concentrator (molecular weight cutoff $100 \mathrm{kDa}$ ) to total lipid concentration of 10-13 mM. Lipid vesicle preparations were stored at room temperature and used within four weeks. Phospholipid and NBDDOPE concentrations were assessed by determination of total inorganic phosphate (16) and UV-spectrophotometry using an extinction coefficient $21,700 \mathrm{~cm}^{-1} \mathrm{M}^{-1}$, respectively.

\section{LUV Quality Assessment}

Determination of zeta potential, mean vesicle size and, size distribution were performed using Nicomp 380 ZLS Submicron Particle Sizer / Zeta Potential Analyzer (Particle Sizing Systems, Langhorne, PA, USA). A single zeta potential measurement was conducted, which reflected the value from combined liposome samples. Electron microscopy was used to determine unilamellarity of lipid vesicles.

\section{Binding of $A O P A$ to $A L B$ and $A L B_{e}$}

Binding of AOPA to ALB or $\mathrm{ALB}_{\mathrm{e}}$ was analyzed by fluorimetric titration according to Cogan et al. (17). Briefly, fluorescently labeled AOPA was added to PBS containing $1 \mu \mathrm{M}$ ALB or $\mathrm{ALB}_{\mathrm{e}}$ from a concentrated ethanolic stock solution. The molar ratio of AOPA to protein in PBS varied between 0.1 and 3.0. The total ethanol concentration was less than $1.5 \%$ at the end of the titration. An increase in the fluorescence intensity was observed with increasing AOPA concentration at $37^{\circ} \mathrm{C}$. No correction for background levels of AOPA in PBS was necessary since the contribution of AOPA blank to the observed fluorescence intensity in the presence of protein was less than $5 \%$.

Equilibrium Partitioning of AOPA Between Binding Proteins and Acceptor Vesicles.

ALB or $\mathrm{ALB}_{\mathrm{e}}(1 \mathrm{mM})$ in PBS, pH 7.4, was incubated with $0.1 \mathrm{mM}$ AOPA at $37^{\circ} \mathrm{C}$ for 10 minutes and the fluorescence intensity monitored. The protein-AOPA complex was then mixed with negative LUVs, positive LUVs, or neutral LUVs and the mixture was incubated for 20 minutes. Preliminary studies showed that this time period was sufficient to achieve equilibrium partitioning of AOPA. The remaining measured fluorescence reflected only the AOPA bound to protein. The relative partition ratio of AOPA between protein and each lipid vesicle preparation $\left(\mathrm{PR}_{\mathrm{AOPA}}, \mathrm{mol} /\right.$ mol) was calculated as follows:

$\mathrm{PR}_{\mathrm{AOPA}}=\frac{(\% \text { protein }- \text { bound AOPA }) / \mathrm{mM} \text { protein }}{(100-\% \text { protein }- \text { bound AOPA }) / \mathrm{mM} \text { phospholipid }}$

where the numerator is the fluorescence intensity measured after addition of lipid vesicles divided by the fluorescence intensity measured before the addition of lipid vesicles multiplied by 100 .

\section{Transfer Assay}

Transfer kinetics of AOPA from ALB or $\mathrm{ALB}_{\mathrm{e}}$ to different acceptor vesicles were measured using a resonance energy transfer assay as described by Wootan et al. (18). Briefly, $1 \mu \mathrm{M}$ ALB or $\mathrm{ALB}_{\mathrm{e}}$ was incubated with $0.1 \mu \mathrm{M}$ AOPA at $37^{\circ} \mathrm{C}$ until binding equilibrium was reached (as measured by maximum fluorescence intensity). AOPA was stored as a concentrated solution containing ethanol. The ethanol concentration in the incubation mixture was $<0.1 \%(\mathrm{v} / \mathrm{v})$. Lipid vesicles were added to the protein-palmitate complex so that the final molar ratio of lipid vesicles to protein was 100. Upon mixing for less than 5 seconds, the decrease in AOPA fluorescence with time was monitored with RF-5000 Recording Spectrofluorometer P/N 206-12400 (Shimadzu Scientific Instrument Inc. Columbia, Maryland). Excitation was at $361 \mathrm{~nm}$ and emission was monitored at $470 \mathrm{~nm}$. The remaining unchanged 
fluorescence signal reflected the protein-bound AOPA. There was no detectable intensity for the binding protein alone, vesicle alone, or unbound AOPA in PBS at the concentrations used.

Data were collected in photon counting mode at 10 -s intervals for 600 to $1000 \mathrm{~s}$ and analyzed by plotting the variation of fluorescence intensity versus time, fitting to a single exponential equation (18):

$$
F(t)=C_{o} \exp ^{-K t}+C
$$

Where, $\mathrm{C}_{\mathrm{o}}$ is the initial (maximum) fluorescence intensity at zero time, $\mathrm{K}$ is the transfer rate of AOPA from binding protein to acceptor vesicles (units of $\mathrm{s}^{-1}$ ), $\mathrm{t}$ is the time interval (s), and $\mathrm{C}$ is the fluorescence intensity of AOPA which remained bound to the protein at equilibrium. Goodness of fit was assessed by the correlation coefficient which was $>0.9$, absolute sum of squares which was $<$ 0.1 .

\section{Data Analysis}

Data are represented as mean \pm SEM unless otherwise stated. $\mathrm{N}$ is the number of replicates performed for each experiment. Whenever appropriate, data were subjected to non-linear least square regression analysis or linear regression analysis. For statistical comparison between groups student t-test or one-way analysis of variance (ANOVA) was used taking $\mathrm{p}<0.05$ for the level of significance.

\section{RESULTS}

\section{Molecular Weight (MW) and protein isoelectric point (pI)}

The molecular weight of ALB and $\mathrm{ALB}_{\mathrm{e}}$ was determined to be 66,400 and 67,300 , respectively. The range in isoelectric point (pI) for ALB and $\mathrm{ALB}_{\mathrm{e}}$ was 4.8-5.0 and 7.0-7.5, respectively. Thus, ALB contained a net negative charge while $A_{L} B_{e}$ was neutral at physiological $\mathrm{pH}$. Peptide mapping of $\mathrm{ALB}_{\mathrm{e}}$ showed that approximately $37 \%$ of the glutamic acid residues were modified by the addition of the ethylenediamine groups.

\section{LUVS Physical Properties}

Vesicle diameter and zeta potential of the lipid vesicles are shown in Table 1. There was no statistical difference in the mean vesicle size of the three lipid vesicle preparations. Freeze-fracture electron microscopy confirmed unilamellarity of vesicles (data not shown).

\section{AOPA Binding}

Figure 1A shows the fluorescence intensity of AOPA in the presence of ALB, ALB ${ }_{e}$, and PBS. Binding of AOPA to ALB and $\mathrm{ALB}_{\mathrm{e}}$ is shown in Figure 1B and was analyzed according to the method of Cogan et al. (17). The calculated apparent dissociation constant $\left(\mathrm{K}_{\mathrm{d}}\right)$ for ALB and $\mathrm{ALB}_{\mathrm{e}}$ was $0.024 \pm 0.003$ and $0.016 \pm 0.001 \mathrm{mM}$ $(n=4)$, respectively. The apparent number of ligand binding sites for ALB and $\mathrm{ALB}_{\mathrm{e}}$ was calculated to be $n=2$. The data show that ALB and $A_{L} B_{e}$ bind AOPA with comparable affinities. Based on these $\mathrm{K}_{\mathrm{d}}$ values, the protein:ligand molar ratio used in all transfer assays was 10:1, a ratio at which more than $99 \%$ of the AOPA was bound to ALB or ALB $_{\mathrm{e}}$.

Table 1. Physical properties of lipid vesicle preparations.

\begin{tabular}{cccc} 
Physical properties & $\begin{array}{c}\text { Negatively charged } \\
\text { vesicles (negative LUVs) }\end{array}$ & $\begin{array}{c}\text { Neutral vesicles } \\
\text { (neutral LUVs) }\end{array}$ & $\begin{array}{c}\text { Positively charged vesicles (positive } \\
\text { LUVs) }\end{array}$ \\
\hline $\begin{array}{c}\text { Average zeta potential } \\
(\mathrm{mV})\end{array}$ & -18 & -5 & +10 \\
& $199 \pm 37^{*}$ & $200 \pm 39^{*}$ & $222 \pm 35^{*}$ \\
$\begin{array}{c}\text { Mean diameter } \\
(\mathrm{nm} \pm \mathrm{SD})\end{array}$ & $232 \pm 66^{* *}$ & \\
\hline * LUVs in PBS and ** = neutral LUVs in PBS containing $1 \mathrm{M} \mathrm{NaCl.}$ &
\end{tabular}



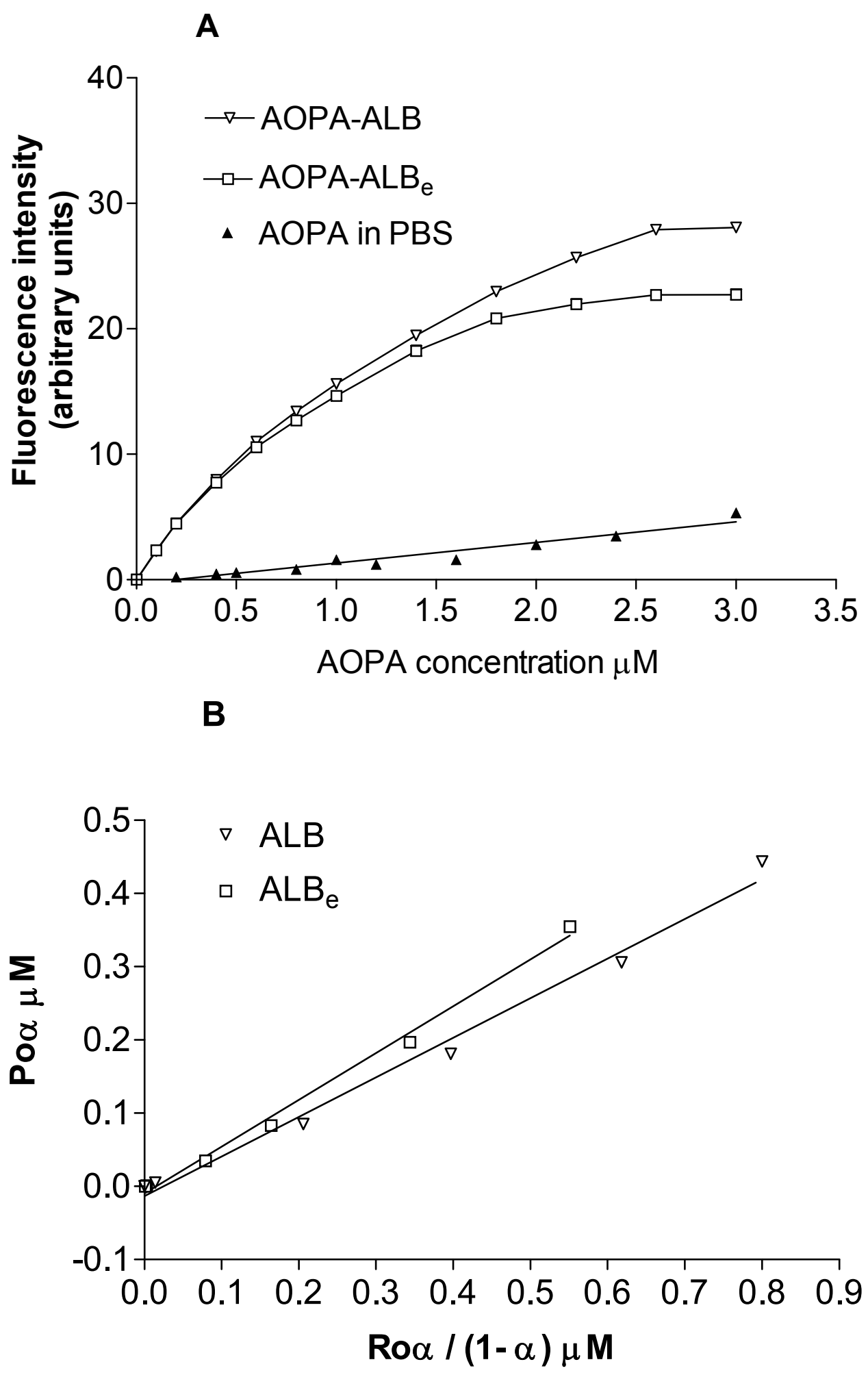

Figure 1. Binding of AOPA to proteins. A: Increase in fluorescence intensity of $1 \mu \mathrm{M}$ ALB $(\nabla)$ or ALB $_{\mathrm{e}}(\square)$ when titrated with increasing concentrations of AOPA. Fluorescence intensity of AOPA alone in PBS is also shown ( $\boldsymbol{\Delta})$. B: binding data of AOPA to ALB or $\mathrm{ALB}_{\mathrm{e}}$ were analyzed as described in Materials and Methods. Po is the total protein concentration, Ro is the total AOPA concentration, and $\alpha$ is the fraction of free binding sites on protein molecule. The apparent $\mathrm{K}_{\mathrm{d}}$ for $\mathrm{ALB}$ and $\mathrm{ALB}_{\mathrm{e}}$ were 0.024 and $0.016 \mu \mathrm{M}$, respectively. 


\section{Partitioning of AOPA Between Binding Proteins and Lipid Vesicles}

The relative distribution of AOPA between ALB or ALB e and lipid vesicles was calculated by measuring the equilibrium fluorescence intensity before the addition of vesicles and the remaining fluorescence intensity after the addition of vesicles according to equation 1. Data in Table 2 are presented as the relative partitioning of AOPA between binding proteins and lipid vesicles. While partitioning of AOPA in the presence of ALB and $\mathrm{ALBe}$ between the negative and positive lipid vesicles was highly significant $(\mathrm{p}<0.0001)$, there was no statistical difference in the partitioning of AOPA between ALB or $\mathrm{ALB}_{\mathrm{e}}$ and the neutral lipid vesicles. AOPA had the greatest preference for positively charged lipid vesicles followed by neutral and lastly negatively LUV. In all cases, partitioning favored binding proteins rather than vesicles.

\section{Effect of Lipid Vesicle Concentration on AOPA Transfer to neutral LUV}

To discriminate between AOPA transfer occurring by aqueous diffusion and that occurring through a direct interaction of protein and acceptor membrane, we examined AOPA transfer from binding protein as a function of increasing acceptor membrane concentration. Figure 2 shows the transfer of AOPA from ALB or $\mathrm{ALB}_{\mathrm{e}}$ to neutral LUV. Prior to the addition of vesicles, there was no statistical difference in the maximum fluorescence intensity between the two proteins. Over a range of phospholipid:protein $(\mathrm{mol} / \mathrm{mol})$ of $20: 1$ to 100:1, the rate of transfer from both proteins increased linearly as the lipid vesicle concentration increased, suggesting that one possibility for the mechanism of fatty acid transfer from proteins is through a collisional interaction of the protein-fatty acid complex with the phospholipid membranes. If the transfer mechanism was solely through aqueous diffusion, we should not expect to see a change in the transfer rate as the number of acceptor vesicles was increased (11). Interestingly the Y-intercepts for the regression lines in Figure 2 were $0.013 \pm$ $0.001 \mathrm{~s}^{-1}$ and $0.009 \pm 0.0003 \mathrm{~s}^{-1}$ for ALB and $\mathrm{ALB}_{\mathrm{e}}$, respectively $(\mathrm{p}<0.05)$. Transfer rates at zero lipid vesicles concentration were estimated to be equivalent to the dissociation of AOPA into an aqueous phase $\left(\mathrm{K}_{\text {off }}\right)(12)$. The $\mathrm{K}_{\text {off }}$ of AOPA-ALB was slower than the $\mathrm{K}_{\text {off }}$ of AOPA-ALB supporting the above results showing that $K_{d}$ of AOPA-ALB is lower than the $\mathrm{K}_{\mathrm{d}}$ of AOPA-ALB.

\section{Effect of Ionic Strength on AOPA Transfer to neutral LUV.}

If transfer of AOPA from extracellular binding proteins to acceptor vesicles occurred through aqueous diffusion, then the rate of transfer may be affected by changing the aqueous solubility of the ligand (12). Conversely, if transfer occurred solely by a collisional interaction, then the transfer rate ought to be unaffected by changes in ligand solubility. Figure 3 shows that an increase in sodium chloride concentration resulted in a nonlinear decrease in the rate of AOPA transfer from ALB or $\mathrm{ALB}_{\mathrm{e}}$. The decrease in transfer rates was linear up to $540 \mathrm{mM}$ sodium chloride. At higher concentrations $(>540 \mathrm{mM})$, the decrease in transfer rate appeared to reach a nadir. Although the results indicate that AOPA transfer must be occurring through diffusion, the observed decrease in the transfer rates due to possible changes in protein binding and/or lipid vesicles integrity by increasing ionic strength cannot be ruled out (see discussion).

Table 2. Relative partitioning of AOPA between protein and lipid vesicles

\begin{tabular}{cccc}
\hline Protein & $\begin{array}{c}\text { Negatively charged } \\
\text { vesicles (negative } \\
\text { LUVs) }\end{array}$ & $\begin{array}{c}\text { Neutral vesicles } \\
\text { (neutral LUVs) }\end{array}$ & $\begin{array}{c}\text { Positively charged } \\
\text { vesicles (positive LUVs) }\end{array}$ \\
\hline ALB & $* 270 \pm 9$ & $229 \pm 9$ & $* 43 \pm 9$ \\
ALB $_{\mathrm{e}}$ & $* 360 \pm 37$ & $219 \pm 3$ & $* 66 \pm 1.3$ \\
\hline
\end{tabular}

Proteins $(1 \mu \mathrm{M})$ were incubated with $0.1 \mu \mathrm{M}$ AOPA at $\mathrm{pH} 7.4$ and $37^{\circ} \mathrm{C}$, as described in Materials and Methods. The fluorescence intensity was measured and the protein-AOPA complex was mixed with neutral, negatively, or positively charged lipid vesicles. At equilibrium, the remaining fluorescence reflected only the AOPA, which remained bound to the protein. The relative distribution of AOPA between protein and vesicles was then calculated using equation 1 . Values are mean $\pm \mathrm{SEM}, \mathrm{n}=4$ to $8 .{ }^{*} \mathrm{p}<0.0001$, 


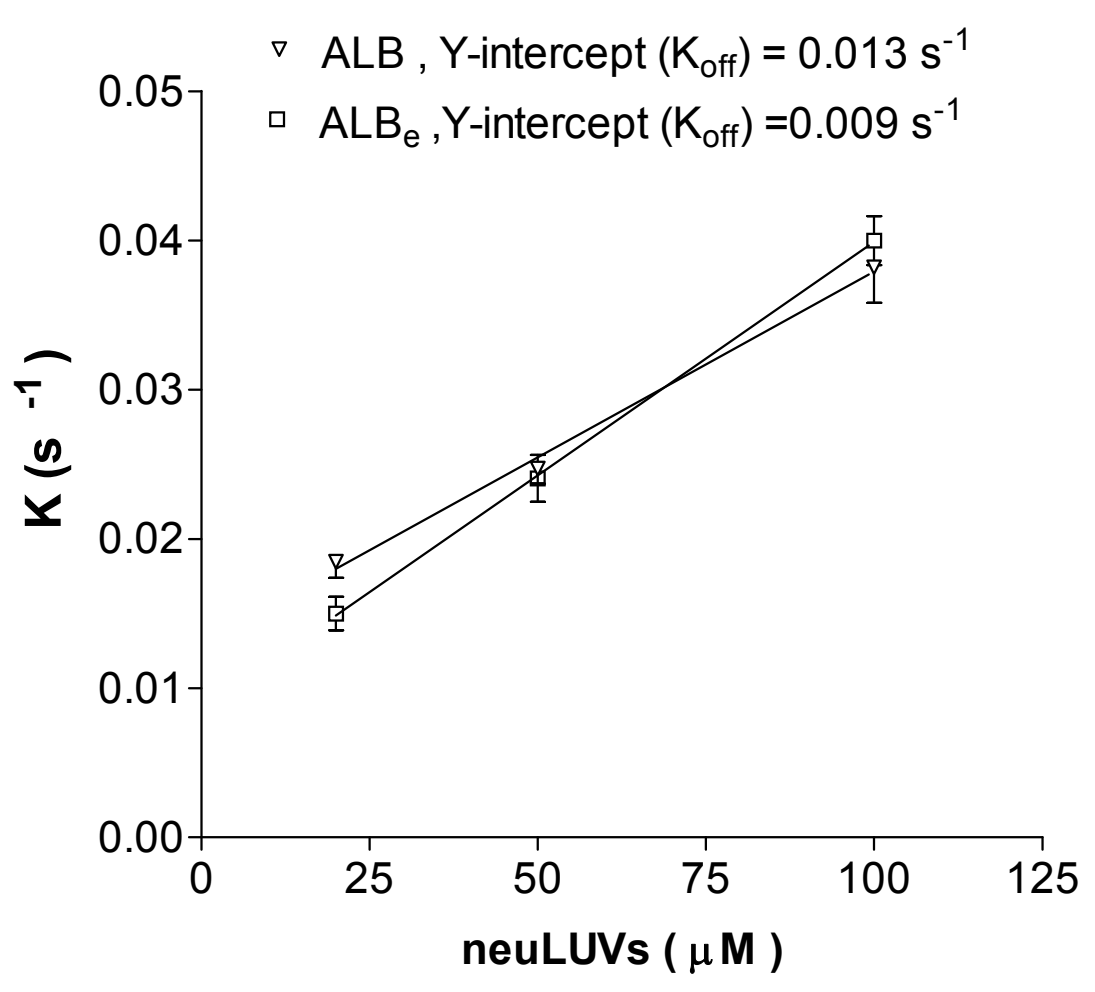

Figure 2. Effect of acceptor membrane concentration on AOPA transfer from binding proteins. The transfer of $0.1 \mu \mathrm{M}$ AOPA from $1.0 \mu \mathrm{M}$ ALB $(\nabla)$ or $\operatorname{ALB}_{\mathrm{e}}(\square)$ to neutral acceptor vesicles. Transfer was monitored at $37^{\circ} \mathrm{C}$. The estimated $\mathrm{K}_{\text {off }}\left(\mathrm{Y}\right.$-intercept at zero lipid vesicles concentration) for ALB and $\mathrm{ALB}_{\mathrm{e}}$ were $0.013 \pm 0.001$ and $0.009 \pm 0.0003 \mathrm{~s}^{-1}$, respectively. Data are mean $\pm \mathrm{SEM}, \mathrm{n}=4$.

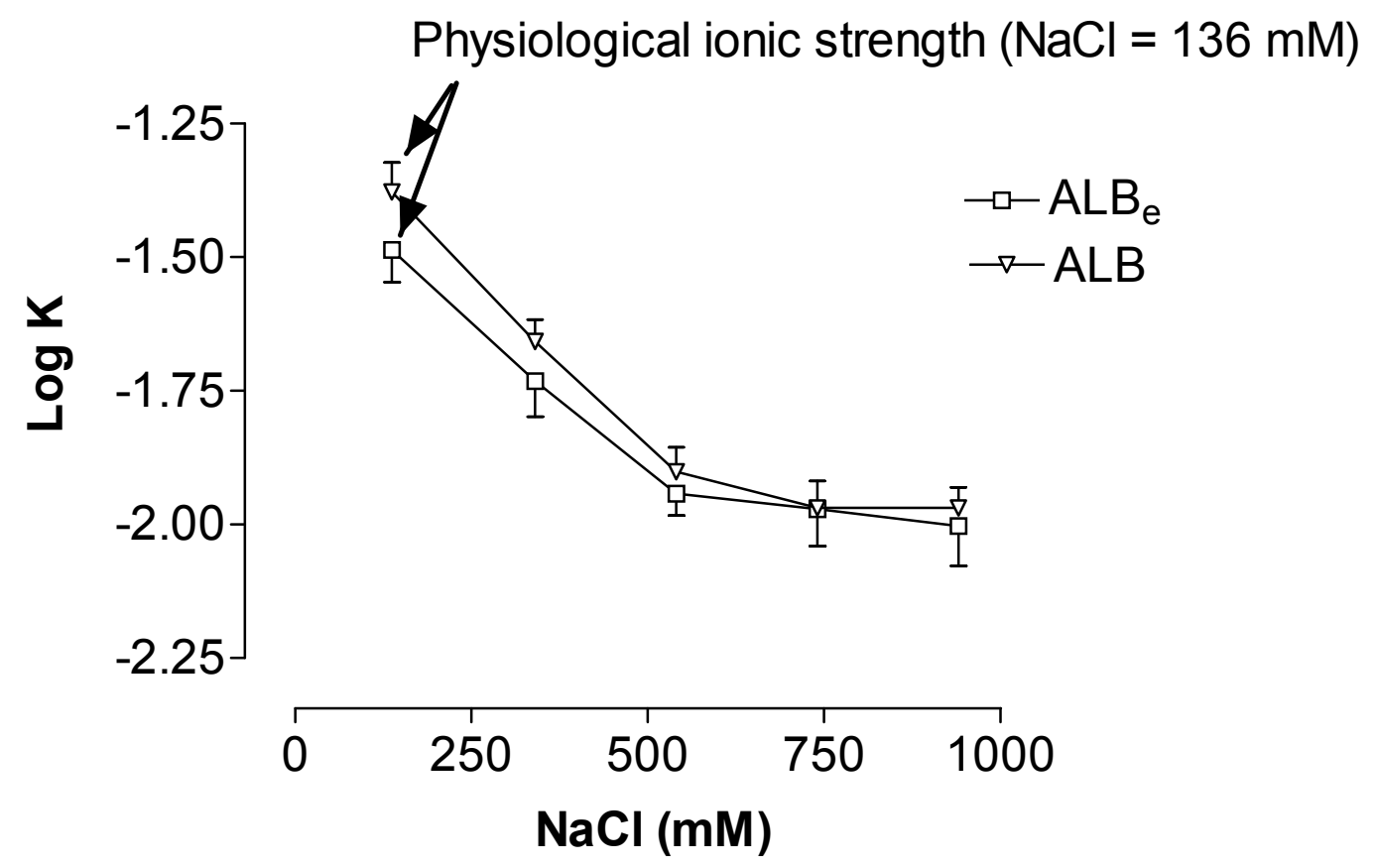

Figure 3. Effect of ionic strength on AOPA transfer from binding proteins. Transfer of $0.1 \mu \mathrm{M}$ AOPA from 1.0 $\mu$ M ALB $(\nabla)$ or $\mathrm{ALB}_{\mathrm{e}}(\square)$ to $100 \mu \mathrm{M}$ neutral acceptor vesicles. Sodium chloride concentration of lipid vesicles and ligand-protein solutions were adjusted before mixing. Data are mean $\pm \mathrm{SEM}, \mathrm{n}=4$. 
Effect of Phospholipid Surface Charge on AOPA Transfer.

To further explore the effect of membrane properties on the transfer rate of AOPA from ALB or $\mathrm{ALB}_{\mathrm{e}}$, we measured the AOPA transfer rates to acceptor membranes of different surface charge. If transfer occurred solely through diffusion then the rate should not be significantly affected by acceptor membrane characteristics. Figure $4 \mathrm{~A}$ and $4 \mathrm{~B}$ show a statistical difference in the transfer rate of AOPA from $\mathrm{ALB}$ and $\mathrm{ALB}_{\mathrm{e}}$ to negatively and positively charged vesicles. Also, the AOPA transfer rate to negatively charged vesicles in the presence of ALB was significantly lower $\left(0.019 \pm 0.001 \mathrm{~s}^{-1}, \mathrm{n}=12\right)$ than that to positively charged vesicles $(0.026 \pm$ $\left.0.0016 \mathrm{~s}^{-1}, \mathrm{n}=8, \mathrm{p}<0.0007\right)$. In contrast, the AOPA transfer rate in the presence of $\mathrm{ALB}_{\mathrm{e}}$ was significantly higher $\left(0.026 \pm 0.0015 \mathrm{~s}^{-1}, \mathrm{n}=4\right)$ when negatively charged vesicles were used as acceptor membranes as compared to positively charged vesicles $\left(0.0135 \pm 0.00054 \mathrm{~s}^{-1}, \mathrm{n}=10, \mathrm{p}<0.0001\right)$.

\section{Effect of ALB Concentration on AOPA Transfer Rate}

To further investigate the role of ALB in AOPA transfer to model membranes, we measured the transfer rate of AOPA to positive LUVs in the presence of 1.0, and $10.0 \mu \mathrm{M}$ ALB and at low AOPA to ALB molar ratio e.g. 0.1. Using these protein concentrations and low AOPA to ALB molar ratio, the free AOPA concentration is predicted to be unchanged and independent on ALB concentration (19). Figure 5 shows that the transfer rate of AOPA from $10 \mu \mathrm{M}$ ALB was significantly higher than from $1.0 \mu \mathrm{M}$ ALB $(\mathrm{p}<0.0001)$. These data imply that the AOPA-ALB bound fraction is an important determinant in transfer.

\section{A - Negatively charged vesicles}

$$
\mathrm{P}<0.005
$$

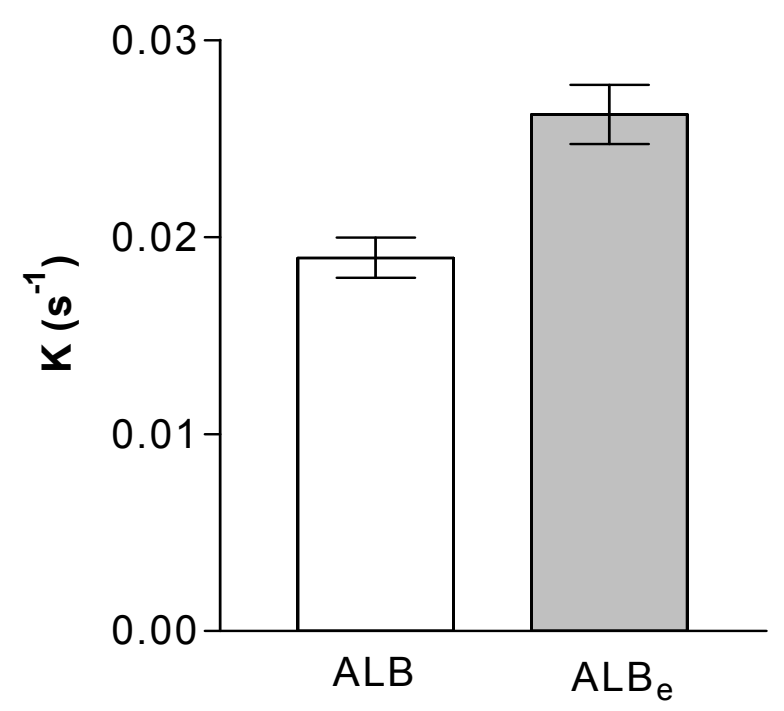

\section{B - Positively charged vesicles}

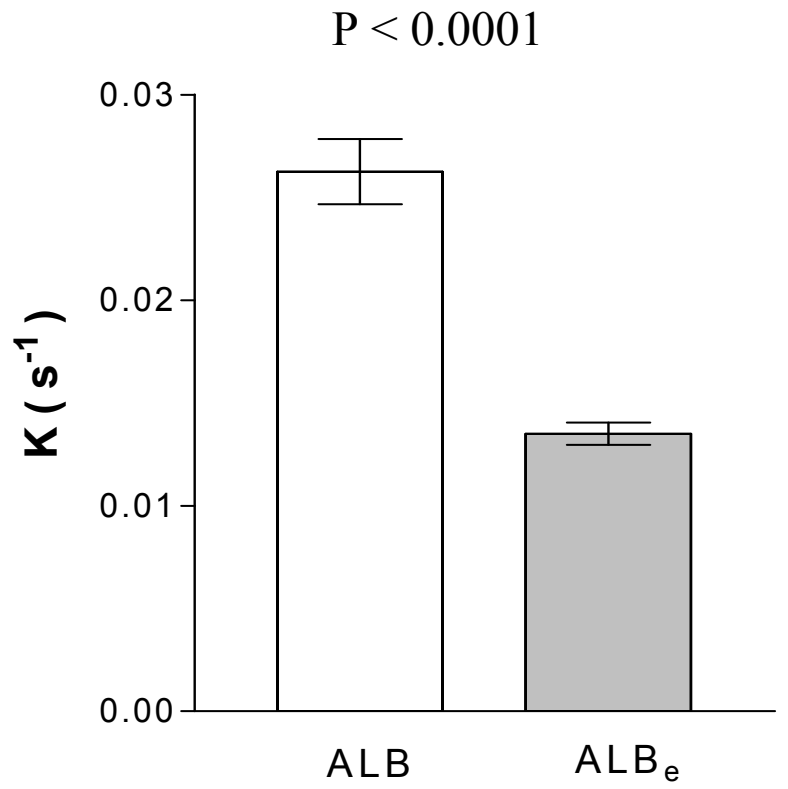

Figure 4. Effect of vesicle surface charge on AOPA transfer. Transfer of $0.1 \mu \mathrm{M}$ AOPA from $1.0 \mu \mathrm{M}$ ALB or ALB to $100 \mu \mathrm{M}$ negative LUVs (in A) or to $100 \mu \mathrm{M}$ positive LUVs (in B). Rates were $0.019 \pm 0.001 \mathrm{~s}^{-1}$ and $0.026 \pm 0.0015 \mathrm{~s}^{-1}$ from ALB and $\mathrm{ALB}_{\mathrm{e}}$, respectively to negative LUVs, (A) or $0.026 \pm 0.0015 \mathrm{~s}^{-1}$ and $0.014 \pm 0.0005 \mathrm{~s}^{-1}$ from ALB and $\mathrm{ALB}_{\mathrm{e}}$ respectively to positive LUVs, (B). Data are mean \pm SEM, $n=4$ to 12 . 


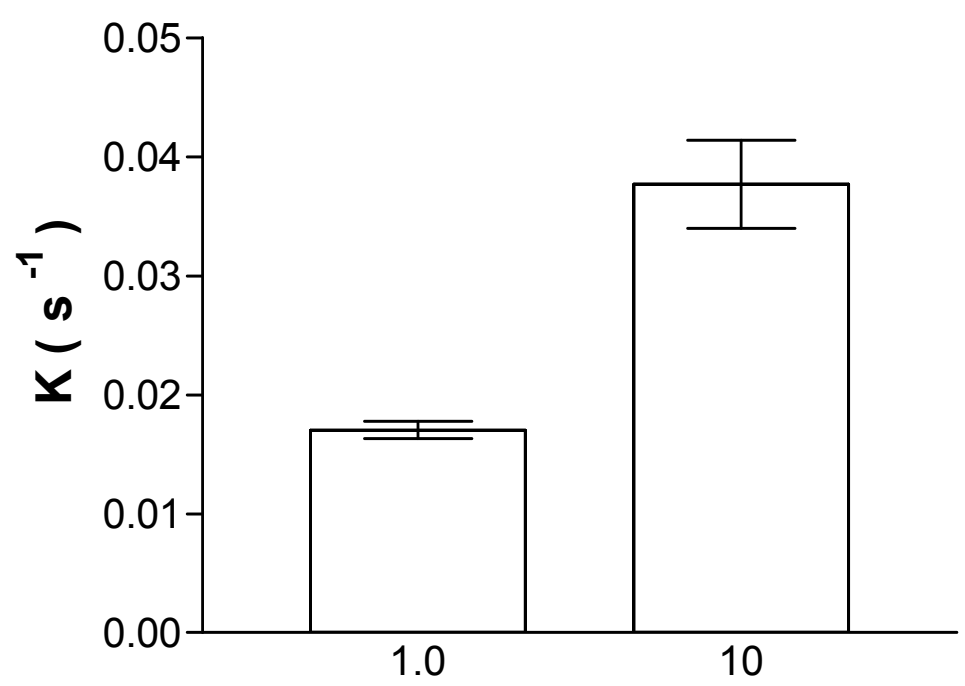

ALB $\mu \mathrm{M}$

Figure 5. Effect of ALB concentration on AOPA transfer. Transfer of AOPA from 1.0, and $10.0 \mu \mathrm{M}$ ALB to $63 \mu \mathrm{M}$ positive LUVs. For the two protein concentrations, AOPA-to-ALB molar ratio was 0.1. Data are mean \pm SEM, $\mathrm{n}=4$. $* \mathrm{p}<0.0001$

\section{DISCUSSION}

The objective of the present study was to elucidate whether the initial transfer process for long-chain fatty acids bound to proteins that differ in their surface charge characteristics is affected by acceptor vesicle membrane surface charge, concentration, and properties of the aqueous phase. One of the first barriers that cellular substrates must overcome prior to cellular entry is binding to the outer membrane leaflet followed by transmembrane flux. Transmembrane flux for long-chain fatty acids is known to occur via diffusion and membrane transport proteins and has been well studied, however, the mechanism responsible for substrates to gain access to and interact with the outer plasma membrane leaflet is less clear. Thus, our study examined the initial transfer of fluorescently labeled palmitic acid (AOPA) from ALB and $\mathrm{ALB}_{\mathrm{e}}$ to LUVs. Results show that: (a) the transfer is a first order process and is best described by a monoexponential equation; (b) the mechanism of transfer involves two processes; an aqueous diffusion-mediated process and a collisionalmediated process; (c) the observed kinetic rate is estimated to be the arithmetic sum of the slower dissociation rate (dissociation of AOPA from its protein binding site into solution, $\mathrm{K}_{\mathrm{off}}$ ) and the faster collisional transfer rate; (d) AOPA transfer that is mediated by a membrane-protein interaction providing the possibility of regulating the movement of these substrates by changing in the membrane composition and structure or the characteristics of the plasma delivery vehicle (e.g., lipid vesicle). These two processes are independent of each other and occur at the same time. Various factors affecting both kinetic processes are discussed below.

We have previously determined the high affinity binding constants $\left(\mathrm{K}_{\mathrm{a}}\right)$ for $\mathrm{ALB}$ and $\mathrm{ALB}_{\mathrm{e}}$ using tracer radiolabeled fatty acid, e.g. $\left[{ }^{3} \mathrm{H}\right]$ palmitic acid, and the heptane: buffer partitioning method $(19,20)$. In this method, the $\left[{ }^{3} \mathrm{H}\right]$ palmitic acid to protein molar ratio was less than 0.1 . Thus, the calculated binding constant $(\mathrm{Ka})$ represents binding of palmitate to the high affinity-binding site on the protein. In the present study we used anthroyloxy labeled fatty acid and fluorimeteric titration ( 0 to 3 moles of AOPA per 1 mole of protein) to determine the equilibrium binding constants for AOPA binding to ALB or ALB $\mathrm{e}_{\mathrm{e}}$. The binding constants calculated in this study were 3fold lower than our previously obtained binding constants for the same proteins. Thus, it may be that, in this study, two fatty acid molecules bind to the first two high affinity binding sites or to the 
high affinity and low affinity binding sites on the protein molecule; the calculated apparent dissociation constants would be the average value of these binding sites. Our calculated binding constants are, however, comparable to the lower values reported in the literature $(21,22)$. To estimate valid transfer rates, it was necessary to determine the $K_{a}$ values for both AOPA-ALB and $A O P A-A_{L}$ in order to calculate the protein concentrations that produce the same unbound ligand concentrations. Since the measured $\mathrm{K}_{\mathrm{a}}$ values were similar, the ALB and $\mathrm{ALB}_{\mathrm{e}}$ concentrations were also similar in the transfer experiments.

Measurement of equilibrium partitioning of AOPA between ALB or $\mathrm{ALB}_{\mathrm{e}}$ and each lipid vesicle preparation shows that partitioning of AOPA favors binding protein over membrane phospholipids by an order of magnitude. Therefore, it was necessary to use higher acceptor to donor ratios in the transfer assay experiments to ensure that unidirectional transfer is monitored. Data in Table 2 show that AOPA has the greatest preference for positively charged lipid vesicles. Second preference was for negatively charged lipid vesicles and the least preference was for neutral lipid vesicles. While there is no difference in the partitioning of AOPA between ALB or $\mathrm{ALB}_{e}$ and neutral LUVs, the observed significant difference in the partitioning of AOPA between both proteins and charged lipid vesicles indicates that charged surface groups might regulate the distribution of AOPA between protein and charged lipid vesicles. Our AOPA partitioning data using neutral lipid vesicles are comparable with the equilibrium distribution of $\left[{ }^{3} \mathrm{H}\right]$ palmitic acid between albumin and lipid vesicles prepared from phosphatidylcholine (palmitate: albumin molar ratio $\left.=2 ; \mathrm{K}_{\mathrm{eq}}=310\right)(23)$.

The possibility that AOPA transfer from binding protein to acceptor lipid vesicles occurs via a collisional mechanism was examined by increasing the concentration of the acceptor membranes and thereby the number of vesicles available for collisional interaction with the AOPAprotein complex. If this mechanism is important in the transfer process, then we expect an increase in the AOPA transfer rate as the acceptor membrane concentration increases (12). This is clearly the case, as seen in Figure 2. By increasing lipid vesicles concentration, there was an increase in the quenching of AOPA fluorescence, which reflect more transfer of AOPA to the lipid vesicle membrane. The observed rates are estimated to be equal to the dissociation rates of AOPA from binding proteins into water $\left(\mathrm{K}_{\mathrm{off}}, \mathrm{Y}\right.$-intercepts in Figure 2) plus collision-mediated transfer rates.

Our estimated low $\mathrm{K}_{\text {off }}$ values are reasonably comparable to the lower values reported in the literature if one considers the differences in FFA: ALB molar ratios used in this study and other studies (24-26). Using albumin-agarose as an acceptor, we previously determined the albuminpalmitate dissociation rate constant to be approximately $0.07 \mathrm{~s}^{-1}(2,20)$. This value is higher than that estimated in this study. The higher $\mathrm{K}_{\text {off }}$ value determined previously may be overestimated if part of the FFA transfer occurred through direct collisional interaction between FFA-ALB complex and the agarose beads.

To further examine the mechanism(s) through which AOPA is transferred to lipid vesicles, we altered its aqueous solubility by increasing the solution ionic strength (Figure 3). If the aqueous solubility of AOPA is not an important factor in the transfer process, we do not expect a linear change in the transfer rate with increasing ionic strength. The data in Figure 3 demonstrate that the transfer rate decreases nonlinearly with increasing salt concentration, suggesting that one possible form of the transfer process may occur via aqueous phase diffusion. Another possible explanation for the effect of high ionic concentration on the transfer rate is that the hydrophobic and electrostatic protein-membrane interactions are disrupted by high salt concentrations, which may affect the transfer rate (27). The observation that the decrease in the transfer rate appears to level off with further increase in salt concentration suggests that the diffusion-mediated transfer is not the only mechanism taking place in the transfer process and that some interaction of the ligand-protein complex with lipid vesicles (collision-mediated transfer) may occur. We have determined the possibility that increasing salt concentration might affect the lipid bilayer structure and / or lipid vesicle mean size. Increasing $\mathrm{NaCl}$ concentration causes vesicle fusion, as indicted by the increase in vesicle mean size and a broader particle size distribution (Table 1). The changes in physical structure of the lipid vesicles may, in part, explain the decrease in the transfer rate of AOPA from ALB or $\mathrm{ALB}_{\mathrm{e}}$. It also has been shown that fluorescence polarization of 
DPH incorporated into SUVs is increased as ionic strength increases, indicating an increase in the phospholipid acyl chain order (28). The possibility that the binding of AOPA to ALB or $\mathrm{ALB}_{e}$ is affected by increasing $\mathrm{NaCl}$ concentration is unlikely, since the observed relative maximum fluorescence intensity at each $\mathrm{NaCl}$ concentration compared to the maximum fluorescence intensity at physiological ionic strength was similar.

The hallmark difference between transfer occurring through collision and that occurring through aqueous diffusion is the effect of acceptor membrane properties and / or the ligand-protein surface charge on the transfer rate $(12,29)$. In order to examine the effect of lipid vesicle surface charge on the transfer rates, we used three lipid vesicle preparations with similar properties and different net surface charge. Zeta potential measurements (Table 1) confirmed the proper vesicle charge. Data in Figure 4 show that the transfer of AOPA bound to ALB ( $\mathrm{pI}=4.8-5.0)$ was significantly faster to positive LUVs than to negative LUVs. In contrast, the transfer rate of AOPA bound to $\mathrm{ALB}_{\mathrm{e}}(\mathrm{pI}=7.0$ 7.5) was significantly faster to negative LUVs than to positive LUVs. The observed effect of the surface charge may reflect an electrostatic interaction between charged phospholipid head groups in the membrane and opposite charges on the AOPA-protein complex. Another possible explanation is that the presence of charged head groups on the membrane phospholipids might cause secondary changes in the membrane bilayer structure e.g. phospholipid head group packing order in the membrane. These secondary changes could increase or decrease the accessibility of binding protein to the lipophilic site of the membrane.

The observed differences in AOPA transfer rates to charged LUVs are unlikely due to differences in vesicle size and / or lamellarity since the particle size measurement (Table 1) and electron microscopic studies showed that the three vesicle preparations were similar.

In an attempt to elucidate the role of ALB in the transfer process, we measured the AOPA transfer rate in the presence of two low ALB concentrations at a fixed AOPA to ALB molar ratio. Under this condition, the free AOPA concentration is predicted to be unchanged for the two ALB solutions (19). If the transfer process occurs solely from the unbound AOPA fraction and independent of ALB concentration, we do not expect to see a difference in the measured transfer rates. Data in Figure 5 show that transfer rate increased significantly with increasing ALB concentration. This result suggests that transfer of AOPA occurs from both the free and the protein-bound pools.

In summary, we provide evidence for the direct transfer mechanism of FFA bound to bovine serum albumin to lipid membranes. In contrast to the known aqueous diffusion mechanism observed for transfer of lipophilic compounds such as cholesterol and phospholipids, bovine serum albumin does not only function as an extracellular buffer for FFA levels but also as a delivery vehicle via its direct interaction with membranes. This provides a mechanism through which an efficient targeting of tightly bound substrates to the cell membranes is preserved. Our results support other reports showing the effect of albumin binding on cellular uptake $(30,31)$ as well as our previous report that electrostatic interactions between the albuminligand complex and hepatocyte or myocyte surfaces modulate the kinetics of free fatty acid uptake (2, 20). Furthermore, our work showed that at a constant concentration of unbound palmitate, there is a positive relationship between hepatocyte- $\left[{ }^{3} \mathrm{H}\right]$ palmitate uptake and total albumin concentration (32). Thus, the unique function of serum albumin to interact with the cell surface is particularly important during cell differentiation when a change in plasma membrane composition occurs which may affect the targeting of extracellular FFA by influencing the rate of FFA transfer from albumin. Overall, the results presented in this study set the framework for future work directed at elucidating the specific structural features of drug delivery vehicles involved in targeting cells.

\section{ACKNOWLEDGMENT}

We thank Mr. Ashok Prashar, Novapharm Biotech Inc. Canada, and Mr. Greg Pokrajac, Particle Sizing Systems, USA for help in particle size and size distribution determination of lipid vesicles. Dr. Y. M. She, Department of Physics and Astronomy, Faculty of Science, University of Manitoba, Canada, for help in analysis of mass spectra. This work was supported from Canadian Institute of Health Research and the Manitoba Health Research Council. 


\section{REFERENCES}

1. Burczynski, F. J., and Luxon, B. A. Is there facilitated uptake of fatty acids by the liver? Interpretation and analysis of experimental data, Canadian Journal of Physiology and Pharmacology, 1995; 73, 409-420.

2. Burczynski, F. J., Wang, G. Q., and Hnatowich, M. Effect of binding protein surface charge on palmitate uptake by hepatocyte suspensions, Br J Pharmacol, 1997; 120, 1215-1220.

3. Weisiger, R., Gollan, J., and Ockner, R. Receptor for albumin on the liver cell surface may mediate uptake of fatty acids and other albumin-bound substances, Science, 1981; 211, 1048-1051.

4. Paris, S., Samuel, D., Jacques, Y., Gache, C., Franchi, A., and Ailhaud, G. The role of serum albumin in the uptake of fatty acids by cultured cardiac cells from chick embyro, European Journal of Biochemistry, 1978; 83, 235-243.

5. Galis, Z., Ghitescu, L., and Simionescu, M. Fatty acids binding to serum albumin increases its uptake and transcytosis by the lung capillary endothelium, European Journal of Cell Biology, 1988; 47, 358365.

6. Antohe, F., Dobrila, L., Heltianu, C., Simionescu, N., and Simionescu, M. Albumin-binding proteins function in the receptor-mediated binding and transcytosis of albumin across cultured endothelial cells, European Journal of Cell Biology, 1993; 60, 268-275.

7. McLean, L. R., and Phillips, M. C. Mechanism of cholesterol and phosphatidylcholine exchange or transfer between unilamellar vesicles, Biochemistry, 1981; 20, 2893-2900.

8. Arvinte, T., and Hildenbrand, K. N-NBD-L-alphadilauroylphosphatidylethanolamine. A new fluorescent probe to study spontaneous lipid transfer, Biochim Biophys Acta, 1984; 775, 86-94.

9. Pownall, H. J., Hickson, D., Gotto, A. M., Jr., and Massey, J. B. Kinetics of spontaneous and plasmastimulated sphingomyelin transfer, Biochim Biophys Acta, 1982; 712, 169-176.

10. Doody, M. C., Pownall, H. J., Kao, Y. J., and Smith, L. C. Mechanism and kinetics of transfer of a fluorescent fatty acid between single-walled phosphatidylcholine vesicles, Biochemistry, 1980; 19, 108-116.

11. Wootan, M. G., and Storch, J. Regulation of fluorescent fatty acid transfer from adipocyte and heart fatty acid binding proteins by acceptor membrane lipid composition and structure, J Biol Chem, 1994; 269, 10517-10523.

12. Hsu, K. T., and Storch, J. Fatty acid transfer from liver and intestinal fatty acid- binding proteins to membranes occurs by different mechanisms,
Journal of Biological Chemistry, 1996; 271, 1331713323.

13. Hoare, D. G., and Koshland, D. E. J. A method for the quantitative modification and estimation of carboxylic acid groups in proteins, Journal of Biological Chemistry, 1967; 242, 2447-2453.

14. Verentchikov, A. N., Ens, W., and Standing, K. G. Reflecting time-of-flight mass spectrometer with an electrospray ion source and orthogonal extraction., Anal-Chem, 1994; 66(61): 126-133.

15. Swairjo, M.A., Roberts, M.F., Campos, M.B., Dedman, J.R., and Seaton, B.A. Annexin V binding to the outer leaflet of small unilamellar vesicles leads to altered inner-leaflet properties: 31P- and 1H-NMR studies. Biochemistry, 1994; 33.1094410950 .

16. Ames, B. N. Assay of Phosphate and Phosphatases, Methods in Enzymology, 1966; 8, 115-117.

17. Cogan, U., Kopelman, M., Mokady, S., and Shinitzky, M. Binding affinities of retinol and related compounds to retinol binding proteins, Eur $J$ Biochem, 1976; 65, 71-78.

18. Wootan, M. G., Bernlohr, D. A., and Storch, J. Mechanism of fluorescent fatty acid transfer from adipocyte fatty acid binding protein to membranes, Biochemistry, 1993; 32, 8622-8627.

19. Elmadhoun, B. M., Wang, G. Q., Templeton, J. F., and Burczynski, F. J. Binding of [H-3]palmitate to BSA, American Journal of Physiology, 1998; 275, G638-G644.

20. Elmadhoun, B. M., Wang, G., Kirshenbaum, L. A., and Burczynski, F. J. Palmitate uptake by neonatal rat myocytes and hepatocytes. Role of extracellular protein, Eur J Biochem, 2001; 268, 3145-3153.

21. Moran, J. B., Burczynski, F. J., Cheek, R. F., Bopp, T., and Forker, E. L. Protein binding of palmitate measured by transmembrane diffusion through polyethylene, Analytical Biochemistry, 1987; 167, 394-399.

22. Spector, A. A., Fletcher, J. E., and Ashbrook, J. D. Analysis of long-chain free fatty acid binding to bovine serum albumin by determination of stepwise equilibrium constants, Biochemistry, 1971; 10, 3229-3232.

23. Daniels, C., Noy, N., and Zakim, D. Rates of hydration of fatty acids bound to unilamellar vesicles of phosphatidylcholine or to albumin, Biochemistry, 1985; 24, 3286-3292.

24. Weisiger, R. A., and Ma, W. Uptake of oleate from albumin solutions by rat liver. Failure to detect catalysis of the dissociation of oleate from albumin by an albumin receptor, Journal of Clinical Investigations, 1987; 79, 1070-1077.

25. Svenson, A., Holmer, E., and Anderson, L. A new method for the measurement of dissociation rates for complexes between small ligands and proteins 
applied to the palmitate and bilirubin complexes with serum albumin, Biochimica et Biophysica Acta, 1974; 342, 54-59.

26. Burczynski, F. J., and Cai, Z.-S. Palmitate uptake by hepatocyte suspension: effect of albumin, American Journal of Physiology, 1994; 267, G371G379.

27. Jones, R. M., Prasad, M. R., and Das, D. K. Modulation of fatty acid-binding capacity of heart fatty acid-binding protein by oxygen-derived free radicals, Mol Cell Biochem, 1990; 98, 161-166.

28. Storch, J., and Kleinfeld, A. M. Transfer of longchain fluorescent free fatty acids between unilamellar vesicles, Biochemistry, 1986; 25, 17171726.

29. Butko, P., Hapala, I., Scallen, T. J., and Schroeder, F. Acidic phospholipids strikingly potentiate sterol carrier protein 2 mediated intermembrane sterol transfer, Biochemistry, 1990; 29, 4070-4077.

30. Fleischer, A. B., Shurmantine, W. O., Luxon, B. A., and Forker, E. L. Palmitate uptake by hepatocyte monolayers. Effect of albumin binding, Journal of Clinical Investigations, 1986; 77, 964-970.

31. Fleischer, A. B., Shurmantine, W. O., Thompson, F. L., Forker, E. L., and Luxon, B. A. Effect of a transported ligand on the binding of albumin to rat liver cells, Journal of Laboratory and Clinical Medicine, 1985; 105, 185-189.

32. Burczynski, F. J., Wang, G., Elmadhoun, B. M., She, Y., Roberts, M. S., and Standing, K. G. Hepatocyte [3H]-Palmitate Uptake: Effect of Albumin Surface Charge Modification., Can J Physiol Pharmacol, 2001; 79, 868-875. 